\title{
Styrene oligomerization as a molecular probe reaction for zeolite acidity: a UV-Vis spectroscopy and DFT study
}

\author{
Inge L. C. Buurmans, ${ }^{a}$ Evgeny A. Pidko, ${ }^{b}$ Jennifer M. de Groot, ${ }^{a}$ Eli Stavitski, ${ }^{a}$ \\ Rutger A. van Santen ${ }^{b}$ and Bert M. Weckhuysen*a
}

Received 4th February 2010, Accepted 12th April 2010

First published as an Advance Article on the web 14th May 2010

DOI: $10.1039 / \mathrm{c002442b}$

\begin{abstract}
A series of H-ZSM-5 crystallites with different framework $\mathrm{Si} / \mathrm{Al}$ ratios was studied by analyzing the kinetics and reaction mechanism of the oligomerization of 4-fluorostyrene as molecular probe reaction for Brønsted acidity. The formation of carbocationic species was followed by UV-Vis spectroscopy. Three carbocationic products were observed, namely a cyclic dimer, a conjugated linear dimer and a larger, more conjugated carbocation. Rate constants for the formation of all three products show a maximum at a $\mathrm{Si} / \mathrm{Al}$ ratio of 25 . Oligomerization of 4-fluorostyrene within the larger supercages of zeolite H-Y leads solely to cyclic dimers. The experimental observations were rationalized by DFT calculations, which show that the selectivity of the styrene oligomerization is controlled by the steric properties of the intrazeolite micropore voids. Two reaction pathways were considered for the formation of the conjugated linear carbocation. The conventional mechanism involves a hydride transfer between two dimeric hydrocarbons (HCs) in the zeolite pores. We propose an alternative monomolecular path, in which the hydride transfer takes place between a hydrogen atom of a dimeric $\mathrm{HC}$ and a zeolitic proton, yielding a conjugated carbocation and molecular $\mathrm{H}_{2}$. Computed free energies indicate that the preference for a particular reaction mechanism is determined by the local shape of the zeolite micropores.
\end{abstract}

\section{Introduction}

Zeolites are crystalline aluminosilicates that constitute an important group of solids that can be used as heterogeneous catalysts for a wide variety of reactions. ${ }^{1,2}$ The well-defined microporous structures of these materials along with pronounced acidities define the main area of their application, which is acid catalysis. Numerous characterization studies have been performed to reveal the relationship between the molecular structure of zeolitic materials, the catalytic activity and Brønsted or Lewis acidity. ${ }^{3-7}$ A wide variety of acidcatalyzed hydrocarbon transformations can be promoted by zeolites. 8,9 These include important chemical reactions, such as isomerization, oligomerization and cracking of hydrocarbons. ${ }^{1,10}$ Since the 1960 s zeolites have been successfully applied for the catalytic cracking of oil. ${ }^{8,9}$ It is generally believed that carbocations are the important reaction intermediates or transition states for these processes. ${ }^{8,9}$

Zeolite acidity depends, among others, on the framework aluminium concentration. Indeed, by introducing more aluminium atoms in the framework (i.e. at lower $\mathrm{Si} / \mathrm{Al}$ molar ratios), the density of acid sites in the material increases. On the other hand, the strength of the individual acid sites increases when the sites become more isolated. ${ }^{11,12}$ This

${ }^{a}$ Inorganic Chemistry and Catalysis, Debye Institute for

NanoMaterials Science, Utrecht University, Sorbonnelaan 16,

3584 CA Utrecht, The Netherlands.E-mail: b.m.weckhuysen@uu.nl;

Fax: + 31 (0)30251 1027

${ }^{b}$ Schuit Institute of Catalysis, Department of Chemistry and Chemical Engineering, Eindhoven University of Technology, P. O. Box 513,

$5600 \mathrm{MB}$ Eindhoven, The Netherlands behavior is generally known as the next nearest neighbour effect. ${ }^{8,13}$ For that reason the effective acidity of Brønsted acid sites in H-ZSM-5, as calculated by aluminium topological density calculations, is expected to show a maximum around a $\mathrm{Si} / \mathrm{Al}$ ratio of $9.5{ }^{14}$ Furthermore, for the reactivity of zeolites the accessibility of the acid sites plays an important role. By creating mesopores and extra-framework aluminium species upon steaming or acid leaching treatments of the zeolite-based catalysts, enhancement of reactivity is observed. ${ }^{15}$ The partial destruction of the crystalline structure improves the accessibility of the intrazeolite active sites towards large molecules. This favorably affects the catalytic reactivity of the resulting mesoporous zeolite. ${ }^{2,16}$ Elucidating the relationship between acidity, accessibility and reactivity is of great importance for both the fundamental understanding of zeolite catalysis and for the optimization of the catalytic performance.

A wide variety of techniques for the characterization of zeolite acidity is available. ${ }^{1,9,17-19}$ Among the most widely used techniques are IR spectroscopy in combination with various probe molecules, ${ }^{20-22}$ activity analysis in hydrocarbon cracking, ${ }^{23,24}$ temperature-programmed desorption of basic probe molecules such as ammonia ${ }^{25,26}$ or amines ${ }^{27}$ and solidstate NMR spectroscopy. ${ }^{28}$ For example, IR spectroscopy in combination with pyridine, lutidine and collidine as molecular probes provides an accessibility index of the different types of acid sites within zeolite materials.

UV-Vis spectroscopy constitutes another suitable tool to study the reactivity and acidity of zeolite materials. By monitoring the acid catalyzed transformation of a probe molecule, namely the oligomerization of 4-fluorostyrene, with UV-Vis 
spectroscopy, the formation of carbocationic reaction intermediates can be monitored. ${ }^{29-31}$ Substituted styrenes are suitable probe molecules because the various oligomerization products have different UV-Vis spectroscopic signatures and therefore can be studied in situ. Furthermore, depending on the Brønsted acid strength and spatial properties of the microporous structure of the catalyst, formation of specific carbocationic products is expected. This allows the direct investigation of the Brønsted acidity by analyzing the reaction products formed upon styrene oligomerization. Fluorinesubstituted styrene is an attractive candidate as it shows a moderate reactivity towards acid-catalyzed oligomerization, thus allowing time-resolution of the reaction steps and determination of reaction rate constants for the formation of particular carbocations. ${ }^{29-31}$

In this work, we have investigated the reactivity of a series of H-ZSM-5 crystallites with different $\mathrm{Si} / \mathrm{Al}$ ratios by $\mathrm{UV}-\mathrm{V}$ is spectroscopy to establish the relationship between Brønsted acidity and styrene oligomerization reactivity. The product formation within H-ZSM-5 was compared to that in zeolite H-Y. Theoretical calculations (DFT) were used to create a molecular-level picture of the experimental observations.

\section{Experimental}

\section{$2.1 \mathrm{UV}-\mathrm{V}$ is spectroscopy measurements}

UV-Vis spectroscopy studies were performed using an Olympus BX41M upright research microscope provided with a $10 \times 0.3$ NA objective lens. Illumination of the sample was performed using a $75 \mathrm{~W}$ Tungsten lamp. The microscopy setup was equipped with a 50/50 double-viewport tube, which accommodated a CCD video camera (ColorView IIIu, Soft Imaging System $\mathrm{GmbH}$ ) and an optical fibre mount. The microscope was connected to a CCD UV-Vis spectrometer (AvaSpec-2048TEC, Avantes) by a $200 \mu \mathrm{m}$-core fibre. UV-Vis spectroscopy measurements were performed using an in situ cell (Linkam Scientific Instruments FTIR 600) equipped with a temperature controller (Linkam Scientific Instruments TMS 94).

The acidity of H-ZSM-5 materials was studied using a probe molecule that shows a spectral change when exposed to acid sites. 4-Fluorostyrene (Acros Organics, 97\%) was chosen for that purpose since only sufficiently strong acid sites are able to protonate the molecule, which subsequently undergoes an oligomerization reaction that can be studied by the changes in the UV-Vis absorption bands. ${ }^{30}$ With confocal fluorescence microscopy measurements on H-ZSM-5 crystals it was shown that the styrene oligomerization reaction can take place in the micropores of the zeolite. ${ }^{29,31}$

Zeolite ZSM-5 samples (CBV2314, Si/Al = 11.5; ACZeo-ZN030, Si $/ \mathrm{Al}=15 ; \mathrm{ACZeo-ZH030,} \mathrm{Si} / \mathrm{Al}=15$; CBV5524G, $\mathrm{Si} / \mathrm{Al}=25 ; \mathrm{CBV8014}, \mathrm{Si} / \mathrm{Al}=40$ and CBV28014, $\mathrm{Si} / \mathrm{Al}=140)$ and zeolite $\mathrm{Y}$ samples (ACZeo-Y307, $\mathrm{Si} / \mathrm{Al}=3.5 ;$ ACZeo-Y411, $\mathrm{Si} / \mathrm{Al}=5.5 ;$ ACZeo-Y530, $\mathrm{Si} / \mathrm{Al}=15 ; \mathrm{ACZeo-Y655,} \mathrm{Si} / \mathrm{Al}=27.5 ; \mathrm{CBV760}$, $\mathrm{Si} / \mathrm{Al}=30$ and $\mathrm{CBV780}, \mathrm{Si} / \mathrm{Al}=40$ ) were obtained from Albemarle Corporation and Zeolyst International in either $\mathrm{NH}_{4}{ }^{+}$- or $\mathrm{H}^{+}$-form. Prior to first use all $\mathrm{NH}_{4}{ }^{+}$-samples were
Table 1 Overview of the H-ZSM-5 materials under investigation

\begin{tabular}{lllll}
\hline & $\begin{array}{l}\mathrm{Si} / \mathrm{Al} \\
\text { molar } \\
\text { ratio }\end{array}$ & $\begin{array}{l}t \text {-Plot external } \\
\text { surface } \\
\text { area } / \mathrm{m}^{2} \mathrm{~g}^{-1}\end{array}$ & $\begin{array}{l}t \text {-Plot } \\
\text { micropore } \\
\text { volume } / \mathrm{cm}^{3} \mathrm{~g}^{-1}\end{array}$ & $\begin{array}{l}\mathrm{BET} \\
\text { surface } \\
\mathrm{area} / \mathrm{m}^{2} \mathrm{~g}^{-1}\end{array}$ \\
\hline ZSM5-1 & 11.5 & 120 & 0.13 & 370 \\
ZSM5-2 & 15 & 165 & 0.13 & 420 \\
ZSM5-3 & 15 & 160 & 0.11 & 380 \\
ZSM5-4 & 25 & 200 & 0.11 & 405 \\
ZSM5-5 & 40 & 205 & 0.11 & 415 \\
ZSM5-6 & 140 & 110 & 0.12 & 380 \\
\hline
\end{tabular}

heat-treated at $723 \mathrm{~K}$ for $24 \mathrm{~h}$. Preceding all measurements samples were heat-treated in air at $723 \mathrm{~K}$ for $2 \mathrm{~h}$ to remove any absorbed species.

All experiments were performed on $5 \mathrm{mg}$ of zeolite powder, compressed to a pellet at a pressure of 5 ton $\mathrm{cm}^{-2}$ on a Perkin-Elmer 15.011 laboratory press. After heating the pellet to the desired temperature for $10 \mathrm{~min}, 10 \mu \mathrm{l}$ of 4-fluorostyrene was added and UV-Vis absorption spectra were taken every 5 s. $\mathrm{N}_{2}$-physisorption isotherms were recorded using a Micromeritics Tristar 3000 setup operating at $77 \mathrm{~K}$. Prior to physisorption measurements, all samples were dried overnight at $573 \mathrm{~K}$ under a $\mathrm{N}_{2}$ flow. The BET surface area was determined and rounded off to the nearest half dozen. In order to obtain the micropore volume and external surface area (rounded off to the nearest half dozen) of the samples the $t$-plot method was applied to the obtained physisorption isotherms. The results of the structural characterization of the H-ZSM-5 materials used in this study are summarized in Table 1.

\subsection{DFT calculations}

Quantum chemical calculations were performed using the Vienna $A b$ initio Simulation Package (VASP) within density functional theory (DFT). ${ }^{32}$ The gradient-corrected PBE exchange-correlation functional was used. ${ }^{33}$ Electron-ion interactions were described with the projected-augmented wave (PAW) method ${ }^{34,35}$ and for valence electrons a plane wave basis set was applied. The energy cut-off was set to $400 \mathrm{eV}$. The Brillouin zone sampling was restricted to $\Gamma$-point. ${ }^{36}$ In a first step the cell parameters were optimized for the periodic models of full-silica zeolite crystals. The acquired parameters were used in all further calculations. Such computational settings were previously shown to be adequate for an accurate description of catalytic reactivity of zeolites. ${ }^{37-41}$ For all structures full geometry optimizations were performed with the fixed cell parameters using a conjugated gradient algorithm. At the initial step of optimization all atoms of the unit cell were allowed to relax. Convergence at this stage was assumed to be attained when the energy difference between the optimization steps was below $10^{-4} \mathrm{eV}$. At the next step, the local structures of the adsorption complexes were refined by geometry optimization in which only the positions of the atoms of the hydrocarbon species and the Brønsted acid site were relaxed until the forces on each atom were below $0.02 \mathrm{eV} \AA^{-1}$. According to our test calculations such an approximation allows substantial reduction of the computational costs associated with the optimization of the zeolite 
models and at the same time leads to rather accurate results. Even though further relaxation of the structures containing a hydrocarbon species confined in zeolite ZSM-5 with the threshold of $0.02 \mathrm{eV}^{-1}$ applied to all atoms of the model may require up to 100 additional steps, the associated total energy change did not exceed $5 \mathrm{~kJ} \mathrm{~mol}^{-1}$. A modest Gaussian smearing was applied to band occupations around the Fermi level and the total energies were extrapolated to $\sigma \rightarrow 0$.

The used model for the H-ZSM-5 zeolite was a complete, periodically repeated MFI unit cell. All calculations were performed using the orthorhombic structure of ZSM-5. ${ }^{42}$ Unsubstituted styrene was used as a model reagent compound. The parameters of the all-silica MFI orthorhombic structure $\left(\mathrm{Si}_{96} \mathrm{O}_{192}\right)$ after optimization of volume and shape were as follows: $a=20.119 \AA, b=19.767 \AA$, and $c=13.161 \AA$. This compares perfectly with the respective experimental XRD data $(a=20.090 \AA, b=19.738 \AA$, and $c=13.142 \AA) .{ }^{42} \mathrm{By}$ replacing one of the 96 unit cell silicon atoms by an aluminium atom, an MFI lattice with a $\mathrm{Si} / \mathrm{Al}$ ratio of 95 was obtained. The aluminium atom was positioned at the T2 crystallographic site, which creates an acid site at the intersection of the straight channel and the sinusoidal pore. A hydrogen atom, which introduced a Brønsted acid site, was implemented into the structure to obtain a neutral framework.

Similar to our previous studies ${ }^{37,38}$ the periodic model of the zeolite $\mathrm{H}-\mathrm{Y}$ structure used for DFT calculations was a rhombohedral faujasite unit cell $\left(\mathrm{Si}_{48} \mathrm{O}_{96}\right)$. The following optimized parameters of the all-silica zeolite $\mathrm{Y}$ rhombohedral unit cell were calculated: $a=b=c=17.5125 \AA$ A, $\alpha=\beta=\gamma=60.00^{\circ}$. 14 Silicon atoms were replaced by aluminium atoms, which were uniformly distributed over the unit cell according to the Löwenstein-rule. This resulted in a $\mathrm{Si} / \mathrm{Al}$ ratio of 2.43 . Furthermore, 14 hydrogen atoms, which act as Brønsted acid sites, were implemented in the structure to achieve a neutral framework. To test the impact of the framework Al density on the stability of the carbocationic species in faujasite, selected products of styrene dimerization confined in a low-alumina faujasite matrix denoted as USY $(\mathrm{Si} / \mathrm{Al}=47)$ were also considered. In this case a single $\mathrm{Al}$ atom was introduced at the 6-membered ring of the supercage $\left(\mathrm{S}_{\text {II }}\right.$ site). The DFTcomputed formation energies of various linear dimeric styrene species did not differ more than $5 \mathrm{~kJ} \mathrm{~mol}^{-1}$ in $\mathrm{HY}$ compared to USY matrices. Therefore we limit the discussion of the results obtained to the more realistic HY model that is furthermore unbiased by the arbitrarily chosen positioning of framework Al atoms.

Gibbs free energies were computed within the ideal gas approximation at a pressure of $1 \mathrm{~atm}$ and a temperature of $373 \mathrm{~K}$ using the results of frequency analysis performed by means of the finite difference method as implemented in VASP. Using this method, harmonic normal modes were computed. Small displacements $(0.02 \AA)$ of atoms from the extraframework species were used for the estimation of the numerical Hessian matrix. The other zeolitic atoms were kept fixed to their equilibrium positions. For the gas-phase the $\mathrm{H}_{2}$ contributions to the partition functions from translational, rotational and vibrational motions were taken into account, whereas only vibrational degrees of freedom were considered for the species in the zeolite channel.
The energies of formation as calculated with DFT were further corrected for dispersion interactions by adding the contributions from van der Waals intermolecular bonds between the confined hydrocarbon species and the zeolite lattice. The interatomic interactions involved were estimated by computing an additional interatomic Lennard-Jones potential for the DFT-optimized structures as defined in the $\mathrm{CVFF}^{43,44}$ force field with the approach as proposed by Demuth et al. $^{39}$ and Vos et al. ${ }^{40}$ using the GULP program. ${ }^{45}$ The CVFF force field is known to be very accurate for the description of various phenomena associated with the formation and dynamics of hydrocarbon species within the zeolite pores. ${ }^{46,47}$ Previous studies indicated that the addition of the empirical corrections to the results obtained at the PBE level results in both thermodynamic and kinetic parameters very close to those obtained at the higher ab initio level. ${ }^{41,48}$

\section{Results and discussion}

\subsection{UV-Vis spectroscopy measurements}

To the series of H-ZSM-5 zeolite samples with different $\mathrm{Si} / \mathrm{Al}$ ratios (Table 1), 4-fluorostyrene was added at $333 \mathrm{~K}$. The reaction was monitored using in situ UV-Vis spectroscopy. Fig. 1 shows that, upon reaction, three major absorption bands were formed at $520 \mathrm{~nm}, 560 \mathrm{~nm}$ and $610 \mathrm{~nm}$ and that their intensities increased in time. According to Scheme 1 (product 7) and Table 2, the absorption band at $520 \mathrm{~nm}$ corresponds to the formation of a cyclic dimeric carbocation. Absorption at a wavelength of $490 \mathrm{~nm}$ is reported for the comparable compound 4-methoxystyrene upon exposure to acidic zeolites. ${ }^{49,50}$ The band is slightly shifted due to the presence of the electron withdrawing fluorine atom in the case of 4-fluorostyrene. The additional absorption bands around $560 \mathrm{~nm}$ and $610 \mathrm{~nm}$ are due to the presence of a conjugated linear dimeric carbocation (Scheme 1 (product 5) and Table 2) and a larger, more conjugated carbocation, respectively. ${ }^{29,49,51}$

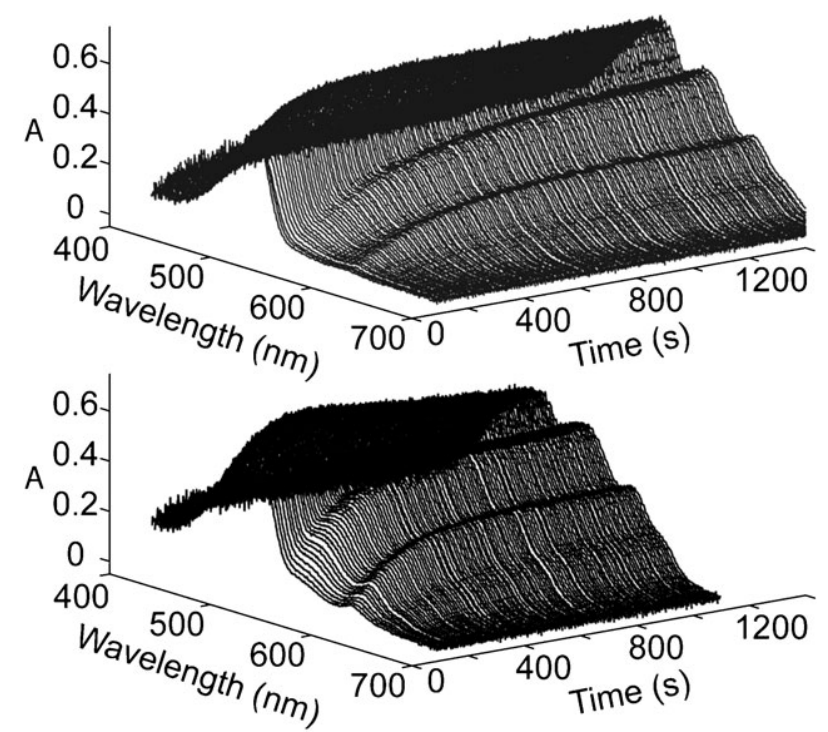

Fig. 1 Examples of the evolution of the UV-Vis absorption bands in time for ZSM5-1 (Si/Al ratio 11.5, top) and ZSM5-4 (Si/Al ratio 25, bottom) upon exposure to 4 -fluorostyrene at $333 \mathrm{~K}$. 


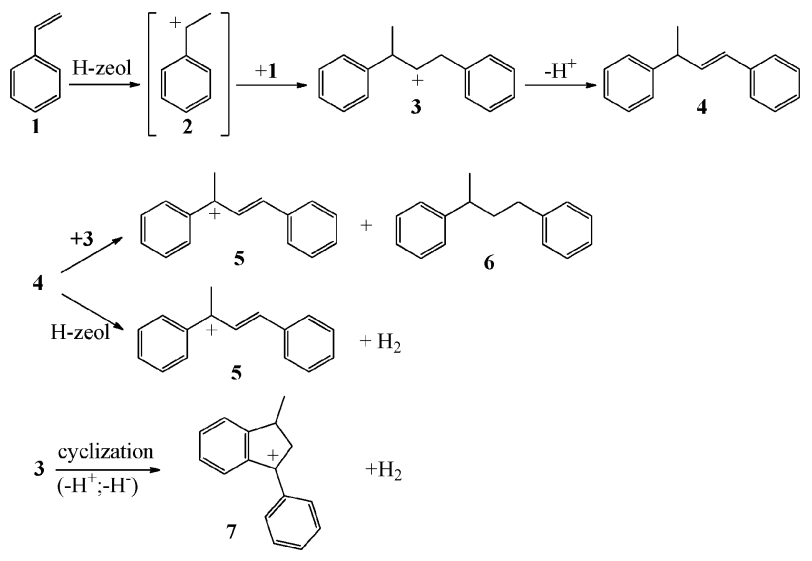

Scheme 1 Potential reaction pathways of the oligomerization reaction of styrene in acidic zeolites. ${ }^{49,51}$ Upon protonation of 4-fluorostyrene (1) by a Brønsted acid site of the zeolite, the initial benzylic carbocation $\mathbf{2}$ is formed. Dimerization with another 4-fluorostyrene monomer (1) can take place to yield the linear dimeric 1,3-bis(4fluorophenyl)-1-butylium cation 3, which can undergo cyclization to the cyclic dimeric 3-methyl-1,4-methoxyphenylindanyl (indanyl) carbocation 7 or undergo a hydride shift to form the conjugated linear dimeric 1,3-bis(4-fluorophenyl)-2-buten-1-ylium (allylic) carbocation 5. A bimolecular pathway for this reaction and a direct hydride transfer from the zeolite framework to the linear dimer are both considered. Further oligomerization will yield larger, more conjugated reaction products.

Table 2 Assignment of the UV-Vis absorption bands of 4-methoxystyrene upon exposure to zeolites

\begin{tabular}{llll}
\hline Sample & $\begin{array}{l}\text { UV-Vis absorption } \\
\text { bands/nm }\end{array}$ & Band assignment & Ref. \\
\hline H-ZSM-5 & $360 ; 580$ & $\begin{array}{l}\text { Benzylic and allylic } \\
\text { carbocation }\end{array}$ & 50,51 \\
H-Y & $360 ; 490 ; 580$ & $\begin{array}{l}\text { Benzylic; indanyl and } \\
\text { allylic carbocation }\end{array}$ & $49-51$ \\
\hline
\end{tabular}

From GC analysis it is known that styrene is converted into a mixture of a linear and a cyclic dimer when using a variety of both liquid and solid acids. ${ }^{52}$ The formation of dimeric products upon exposure of 4-methoxystyrene dissolved in isooctane to $\mathrm{H}-\mathrm{Y}$ and $\mathrm{H}-\mathrm{ZSM}-5$ samples has been demonstrated by UV-Vis spectroscopy. ${ }^{50}$ The extracted styrene products were analyzed using GC, GC-MS, GC-IR, ${ }^{1} \mathrm{H}-\mathrm{NMR}$ and ${ }^{13} \mathrm{C}-\mathrm{NMR}$. In situ IR spectroscopy of acidic zeolites during the reaction with 4-methoxystyrene demonstrates that dimers are the major components in the mixture of organic products. ${ }^{49}$ Furthermore, the experimentally obtained UV-Vis and IR spectra were supported with theoretical calculations at the Hartree-Fock and B3LYP levels to simulate the spectra. ${ }^{53}$ By preparing the conjugated linear dimeric carbocation (5) in solution it was possible to measure its characteristic signals in ${ }^{13} \mathrm{C}$-NMR and compare these to the ${ }^{13} \mathrm{C}$-NMR spectrum as predicted by theoretical calculations. ${ }^{53}$ In addition, an in situ synchrotron-based IR microspectroscopy study, supported by model DFT calculations, on 4-fluorostyrene oligomerization in H-ZSM-5 crystals has clearly indicated the formation of the conjugated linear dimeric carbocations (5) within the straight channels of the zeolite. ${ }^{54}$

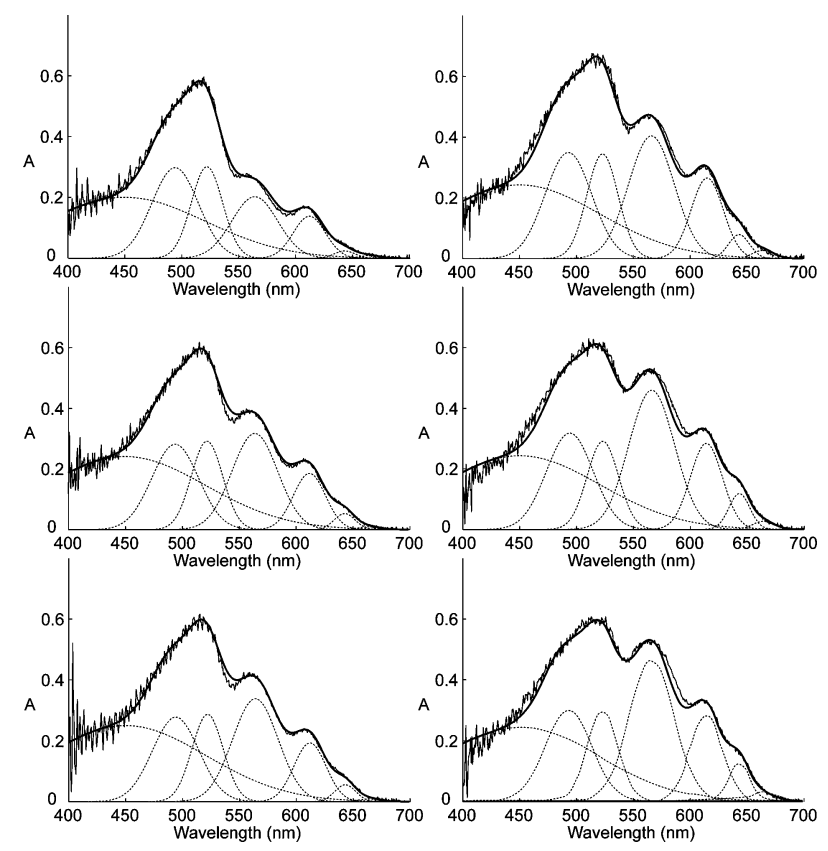

Fig. 2 Examples of the deconvolution procedure for UV-Vis absorption spectra of H-ZSM-5. ZSM5-1 (Si/Al ratio 11.5, left) and ZSM5-4 (Si/Al ratio 25, right) were exposed to 4-fluorostyrene at $333 \mathrm{~K}$. The displayed spectra were taken after 250 (top), 500 (middle) and 600 (bottom) seconds and deconvoluted (black line) with a linear combination of seven Gaussian functions (dashed lines).

The development of the absorption bands in time was followed to determine the reactivity of H-ZSM-5 samples with different $\mathrm{Si} / \mathrm{Al}$ ratios. Since the absorption bands overlap significantly, a deconvolution of the different bands in the UV-Vis spectra was performed and seven Gaussian functions, shown in Fig. 2 and Table 3, were resolved. The Gaussian functions at 494, 522, 565, 613 and $643 \mathrm{~nm}$ determine the shape of the absorption spectrum. The Gaussian at $450 \mathrm{~nm}$ forms a broad background, while the Gaussian function at $664 \mathrm{~nm}$ has only a very small contribution to the overall shape. The positions and widths of the Gaussian bands are independent of the ZSM-5 sample used. The consistency of the deconvolution indicates that the deconvolution as proposed here has physical meaning. Furthermore, the fact that a

Table 3 Overview of the positions and widths of the Gaussian functions used to deconvolute the UV-Vis absorption spectra of the H-ZSM-5 samples under investigation

\begin{tabular}{|c|c|c|}
\hline Sample & $\mathrm{Si} / \mathrm{Al}$ ratio & $\begin{array}{l}\text { Position and width (between brackets) } \\
\text { of Gaussians/nm }\end{array}$ \\
\hline ZSM5-1 & 11.5 & $\begin{array}{l}450(100), 494(29), 522(19.5), \\
565(28.5), 613(20), 643(13), 664(13)\end{array}$ \\
\hline ZSM5-2 & 15 & $\begin{array}{l}450(100), 494(29), 521(19.5) \\
564(28), 613(20), 643(13), 664(13)\end{array}$ \\
\hline ZSM5-3 & 15 & $\begin{array}{l}450(100), 494(29), 521(19.5) \\
563(28), 613(20), 643(13), 664(13)\end{array}$ \\
\hline ZSM5-4 & 25 & $\begin{array}{l}450(100), 494(29), 523(19.5), \\
566(28.5), 614(20), 643(13), 664(13)\end{array}$ \\
\hline ZSM5-5 & 40 & $\begin{array}{l}450(100), 494(29), 523(19.5) \\
566(28), 614(20), 643(13), 664(13)\end{array}$ \\
\hline ZSM5-6 & 140 & $\begin{array}{l}450(100), 494(29), 522(19.5) \\
565(28), 614(20), 643(13), 664(13)\end{array}$ \\
\hline
\end{tabular}


coherent interpretation can be given is another strong point of the deconvolution.

The normalized development of the five Gaussian functions that determine the shape was plotted in time. Two sets of Gaussians with distinct development in time turned out to be present: Gaussian functions at $494 \mathrm{~nm}$ and $522 \mathrm{~nm}$ showed the same time dependent behavior, while the Gaussians at 565, 613 and $643 \mathrm{~nm}$ formed the other type. The two Gaussian functions at $494 \mathrm{~nm}$ and $522 \mathrm{~nm}$ together determine the shape of the product band of the cyclic dimeric carbocation. The three Gaussian functions at 565, 613 and $643 \mathrm{~nm}$ determine the shape of the product bands of the conjugated linear dimeric and the larger carbocation. The fact that the Gaussian functions of the conjugated linear dimeric and the larger, more conjugated carbocation show the same development in time indicates that the larger carbocation is indeed formed upon further oligomerization of the linear dimeric carbocation. This is in good agreement with the reaction mechanism as shown in Scheme 1.

From both types of Gaussians one function was chosen as a representative of the set: using second-order kinetics a fit was made for the development of the Gaussians at 522 and $565 \mathrm{~nm}$ in time. This procedure is depicted in Fig. 3 for the Gaussian function at $565 \mathrm{~nm}$. The second-order kinetic equation used was $d=m_{0} /\left(1+m_{0} k t\right)$, where $d$ is the transient dimer concentration, $m_{0}$ is the initial concentration of reagent and $k$ is the reaction rate constant for a bimolecular conversion.

From the fitting curves as determined for the Gaussians at 522 and $565 \mathrm{~nm}$ reaction rate constants were obtained for samples with different $\mathrm{Si} / \mathrm{Al}$ ratios. Both Gaussian functions indicated the same result: a maximum in reactivity (rate constant) is obtained for the H-ZSM-5 sample with a $\mathrm{Si} / \mathrm{Al}$ ratio of 25 (Fig. 4).

Since neither the external surface area of this zeolite sample nor its micropore volume (see Table 1) shows a maximum in comparison to the other zeolite samples, the higher reactivity can be attributed to an optimum in Brønsted acidity for the

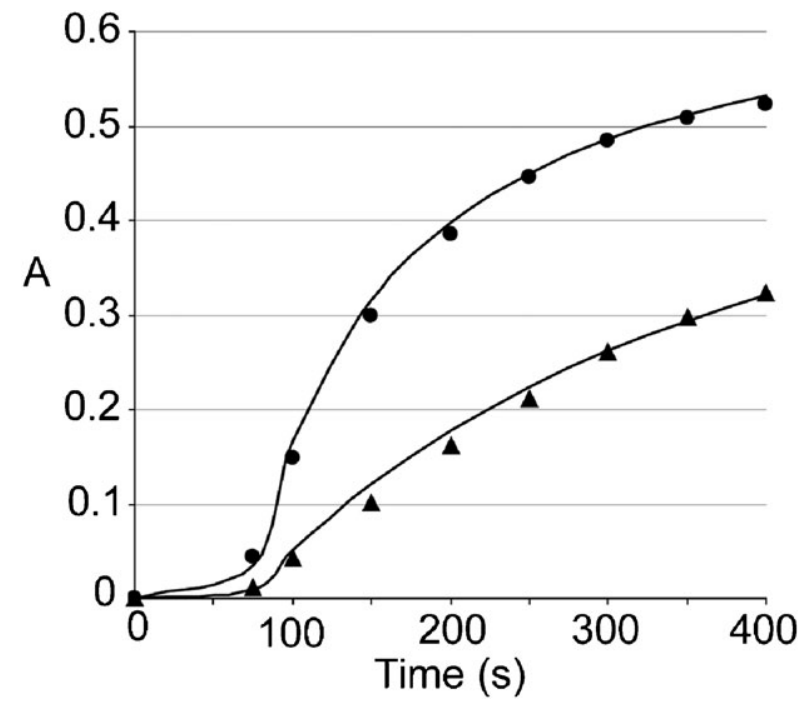

Fig. 3 Absorption of the Gaussian band at $565 \mathrm{~nm}$ as a function of reaction time for ZSM5-1 (triangles) and ZSM5-4 (dots). The lines represent the fitting curves as fitted with second-order kinetics.

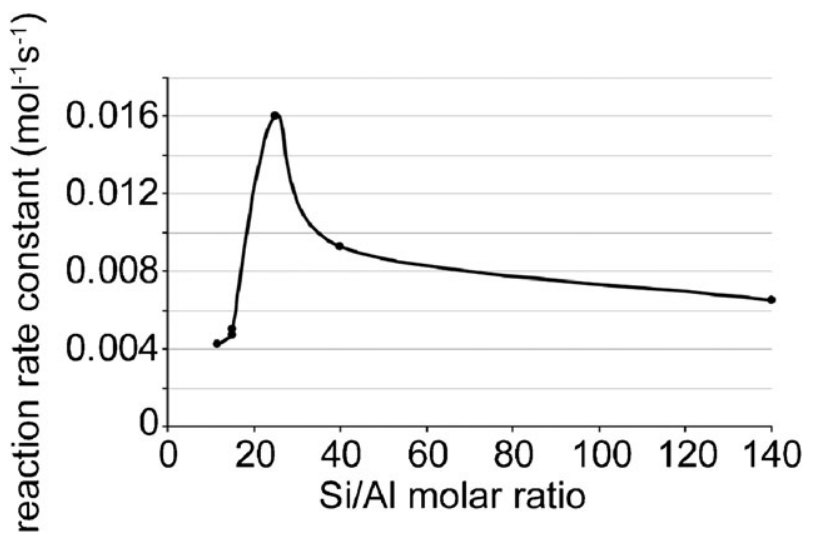

Fig. 4 Reaction rate constants for the reaction of 4-fluorostyrene with H-ZSM-5 samples at $333 \mathrm{~K}$ as determined for the Gaussian function at $565 \mathrm{~nm}$. A maximum in reactivity is obtained for a $\mathrm{Si} / \mathrm{Al}$ ratio of 25. The shown reaction rate constants are an average of two measurements.

oligomerization of styrene. As mentioned previously, from aluminium topological density calculations it is known that the expected maximum in acidity is reached at a $\mathrm{Si} / \mathrm{Al}$ ratio of 9.5. ${ }^{14}$ The theoretical maximum lies at a lower $\mathrm{Si} / \mathrm{Al}$ ratio than observed here, since the oligomerization of styrene requires one protonated and one unprotonated styrene monomer in close proximity to each other. At low $\mathrm{Si} / \mathrm{Al}$ ratios the chance of finding unprotonated styrene molecules is small due to the abundance of acid sites, which slows down the reaction. In a statistical study on the aluminium distribution in ZSM-5 the probability of finding a second aluminium atom within a sphere with a radius of $1 \mathrm{~nm}$ around a given aluminium atom was calculated. ${ }^{55}$ This probability is 1 in a framework with a $\mathrm{Si} / \mathrm{Al}$ ratio of 12 , while the probability is 0.9 for a $\mathrm{Si} / \mathrm{Al}$ ratio of 24 . Since styrenes are quite large molecules, the latter distribution is more beneficial for the styrene oligomerization reaction.

Additional measurements on the oligomerization reaction of 4-fluorostyrene were performed on a zeolite H-Y sample with a $\mathrm{Si} / \mathrm{Al}$ molar ratio of 15 . The obtained UV-Vis spectrum for this reaction at $333 \mathrm{~K}$, as depicted in Fig. 5, shows only one absorption band at a wavelength of $520 \mathrm{~nm}$. This band corresponds to the formation of the cyclic dimeric carbocation. Additionally, zeolite $\mathrm{H}-\mathrm{Y}$ samples with different $\mathrm{Si} / \mathrm{Al}$ ratios

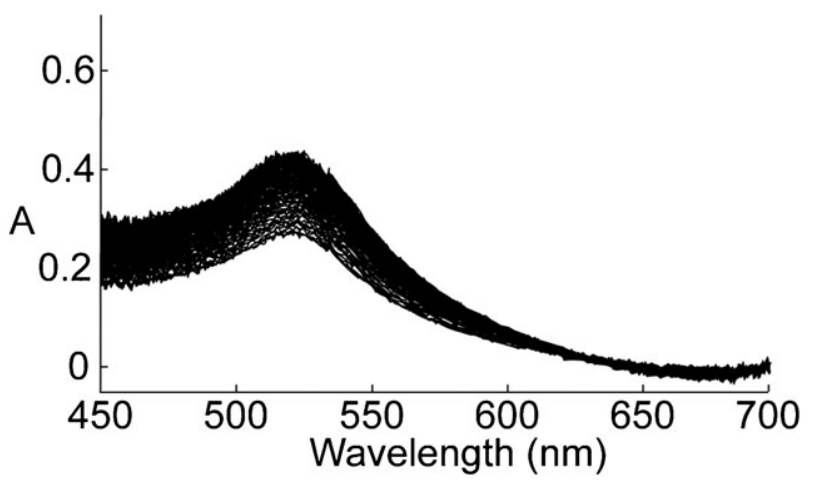

Fig. 5 Example of the evolution of the UV-Vis absorption band in time for zeolite $\mathrm{H}-\mathrm{Y}$ (Si/Al ratio 15$)$ upon exposure to 4-fluorostyrene at $333 \mathrm{~K}$. 
$(3.5,5.5,15,27.5,30$ and 40$)$ were studied during the oligomerization reaction of 4-fluorostyrene. For all samples only formation of the cyclic dimer was found, as they all showed after reaction an absorption maximum at $520 \mathrm{~nm}$.

\subsection{DFT calculations}

Thermodynamics of the oligomerization reaction of styrene in the pores of zeolites H-ZSM-5 and H-Y were further investigated by periodic density functional theory (DFT) calculations. For H-ZSM-5 calculations on the formation of carbocations were performed for a Brønsted acid site at the intersection of the straight channel and the sinusoidal pore. For zeolite $\mathrm{H}-\mathrm{Y}$ formation energies of the carbocations in a supercage were calculated. Formation of the linear dimeric carbocation $\mathbf{5}$ and the cyclic dimeric carbocation 7 confined within H-ZSM-5 (Fig. 6 and 7, respectively) and $\mathrm{H}-\mathrm{Y}$ (Fig. 8) matrices was assumed to proceed via the mechanism proposed by Corma and García. ${ }^{49}$ The corresponding reaction steps are shown in Scheme 1, whereas the computed energies of formation are listed in Table 4. According to Corma and García ${ }^{49}$ the formation of species $\mathbf{5}$ involves a hydride transfer between species $\mathbf{4}$ and $\mathbf{3}$ confined in the microporous matrix. Whereas such a bimolecular reaction could proceed within large supercages of $\mathrm{H}-\mathrm{Y}$, the favorable arrangement of the two bulky hydrocarbon species $\mathbf{3}$ and $\mathbf{4}$ tightly fitted into the pore system of H-ZSM-5 seems unrealistic. Therefore we considered an additional monomolecular reaction pathway for the formation of the conjugated linear dimeric carbocations.
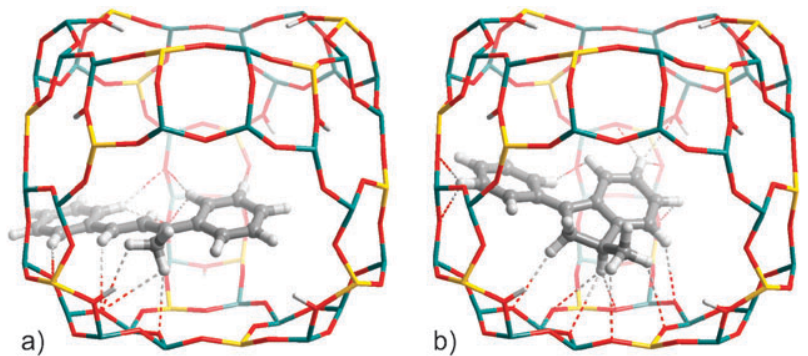

Fig. 8 Optimized structure of (a) 5 and (b) 7 in H-Y zeolite. Dashed lines indicate $\mathrm{CH} \cdots \mathrm{O}_{z}$ intermolecular contacts below $3.2 \AA$.
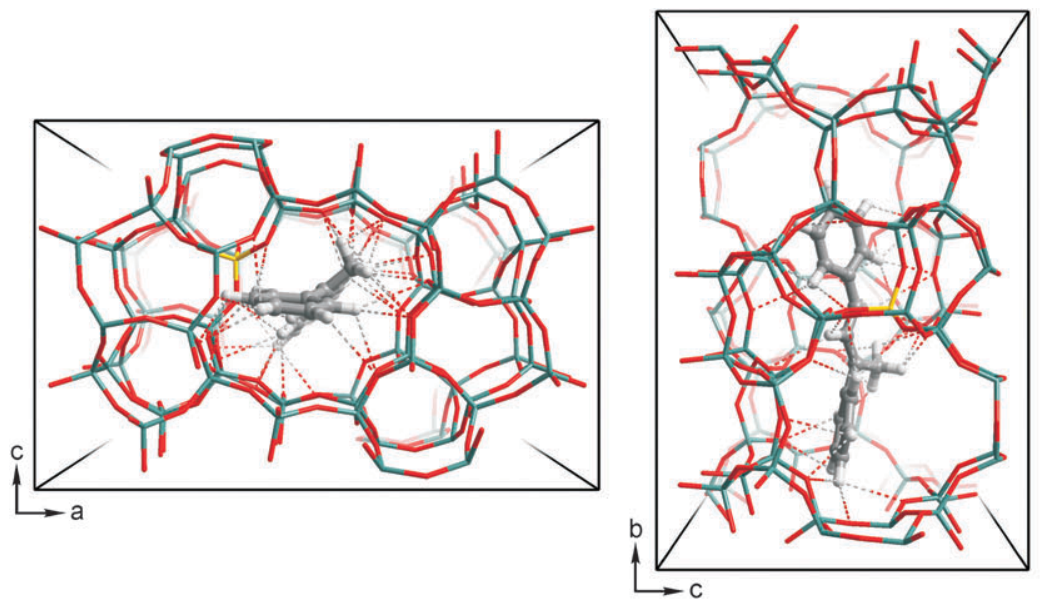

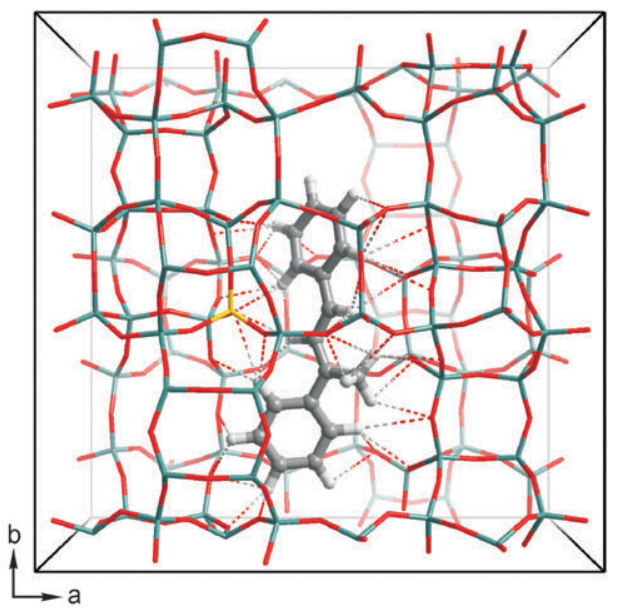

Fig. 6 Optimized structure of 5 in H-ZSM-5 zeolite (views along $b, a$, and $c$ crystallographic axes). Dashed lines indicate $\mathrm{CH}_{\cdots} \cdots \mathrm{O}_{z}$ intermolecular contacts below $3.2 \AA$.

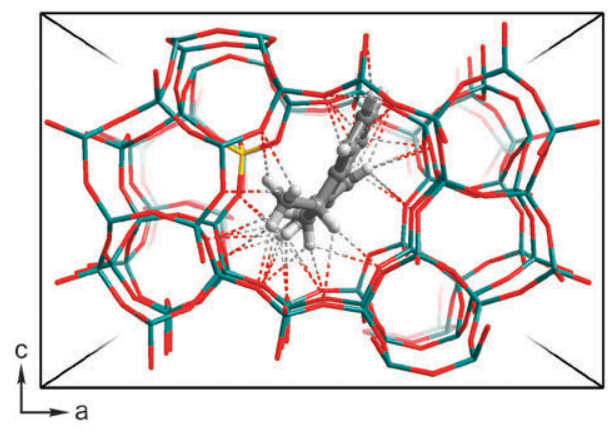

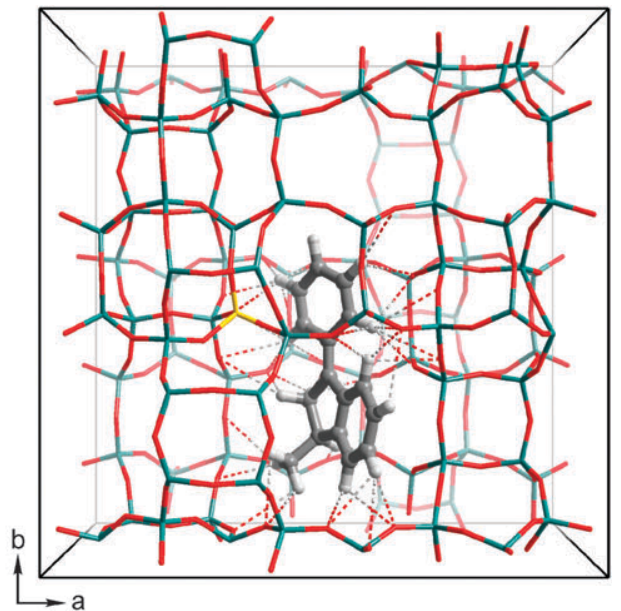

Fig. 7 Optimized structure of 7 in H-ZSM-5 zeolite (views along $b, a$, and $c$ crystallographic axes). Dashed lines indicate $\mathrm{CH}_{\cdots} \cdots \mathrm{O}_{z}$ intermolecular contacts below $3.2 \AA$. 
Table 4 Pure electronic $\left(\Delta E^{\mathrm{PBE}} / \mathrm{kJ} \mathrm{mol}^{-1}\right)$ and corrected for van der Waals interactions $\left(\Delta E^{\mathrm{PBE}+\mathrm{vdW}} / \mathrm{kJ} \mathrm{mol}^{-1}\right)$. DFT computed energies of the reactions shown in Scheme 1

\begin{tabular}{lccccc}
\hline & \multicolumn{2}{c}{$\mathrm{H}-\mathrm{ZSM}-5$} & & $\mathrm{H}-\mathrm{Y}$ & \\
\cline { 2 - 3 } \cline { 5 - 6 } & $\Delta E^{\mathrm{PBE}}$ & $\Delta E^{\mathrm{PBE}+\mathrm{vdW}}$ & & $\Delta E^{\mathrm{PBE}}$ & $\Delta E^{\mathrm{PBE}+\mathrm{vdW}}$ \\
\hline $\mathbf{1} \rightarrow \mathbf{2}$ & +8 & -126 & -11 & -89 \\
$\mathbf{2} \rightarrow \mathbf{3}$ & -6 & -90 & -78 & -129 \\
$\mathbf{3} \rightarrow \mathbf{4}$ & -5 & -7 & -19 & -16 \\
$\mathbf{4}+\mathbf{3} \rightarrow \mathbf{5}+\mathbf{6}$ & -35 & -62 & -62 & -67 \\
$\mathbf{4} \rightarrow \mathbf{5}+\mathrm{H}_{2}$ & +56 & +35 & +60 & +47 \\
$\mathbf{3} \rightarrow \mathbf{7}+\mathrm{H}_{2}$ & +22 & +46 & -20 & -38 \\
\hline
\end{tabular}

It involves recombination of a hydridic $\mathrm{H}$ species at the tertiary carbon atom of $\mathbf{4}$ with an adjacent acidic proton of the zeolite resulting in $\mathbf{5}$ and molecular $\mathrm{H}_{2}$. Although one expects such a dehydrogenation path to be energetically less favorable than the conventional hydride transfer, the substantial entropy gain due to the formation of mobile $\mathrm{H}_{2}$ molecules may favor this path.

The optimized structure of 5 in H-ZSM-5 (Fig. 6) shows ca. 40 short (below $3.2 \AA$ ) intermolecular interactions between oxygen atoms of the zeolite framework and $\mathrm{H}$ species of the carbocation. For the respective structure in the supercage of $\mathrm{H}-\mathrm{Y}$ (Fig. 8a) there are only 13 of those intermolecular contacts, which correspond to van der Waals (vdW) or dispersion interactions. This suggests an important role of these rather weak but numerous contacts in the stabilization of various bulky hydrocarbon species in zeolitic voids, especially in H-ZSM-5 zeolites. However, it is known that DFT calculations fail in their description of such bonds. ${ }^{56}$ Applying empirical or higher-level $a b$ initio corrections to the DFToptimized structures usually yields rather accurate adsorption and reaction energies. ${ }^{39,40,48}$ For that reason we implemented the van der Waals correction into the calculations to achieve a more accurate qualitative picture of the stabilities of various hydrocarbon species in zeolites, especially when formed in the pore system of H-ZSM-5.

When the impact of vdW interactions is neglected $\left(\Delta E^{\mathrm{PBE}}\right)$, the formation of the linear dimeric carbocation $(\mathbf{1} \rightarrow \mathbf{3})$ that is the precursor for both the cyclic and the conjugated linear carbocation is substantially favored in the larger pores of zeolite $\mathrm{H}-\mathrm{Y}$ as compared to the respective process in the pores of H-ZSM-5 $\left(\Delta E^{\mathrm{PBE}}\right.$ values equal -89 and $+2 \mathrm{~kJ} \mathrm{~mol}^{-1}$, respectively). After correcting for the van der Waals interactions between the carbocations and the zeolite framework, the formation of $\mathbf{3}$ becomes equally strongly exothermic for both zeolites. The computed $\Delta E^{\mathrm{PBE}+\mathrm{vdW}}$ values equal $-218 \mathrm{~kJ} \mathrm{~mol}^{-1}$ and $-216 \mathrm{~kJ} \mathrm{~mol}^{-1}$ for $\mathrm{H}-\mathrm{Y}$ and $\mathrm{H}-\mathrm{ZSM}-5$, respectively. The larger contribution of $\mathrm{vdW}$ interactions in the former case is due to the much tighter fit of the dimeric species in the straight pores of H-ZSM-5.

The $\mathrm{CH}_{2}$ group in the resulting carbocation 3 is rather acidic. Thus, at the next step one of its $\mathrm{H}$ atoms is being transferred to the zeolite, yielding the conjugated alkene 4 adsorbed to a zeolitic Brønsted acid site. The driving force for this reaction step is the formation of a delocalized $\pi$-system in the neutral species $\mathbf{4}$ and the energy gain associated with the formation of a $\pi$-complex between the adsorbed alkene and the zeolitic Brønsted acid site. As follows from Table 4, this transformation is slightly exothermic for both framework types, indicating an almost equal stability of $\mathbf{3}$ and $\mathbf{4}$. Since the number of $\mathrm{CH}_{x}$ species and the number of stabilizing $\mathrm{CH} \cdots \mathrm{O}_{z}$ contacts remain constant during this reaction, the $\mathrm{vdW}$-corrected reaction energies are very close to the DFT-computed ones.

The subsequent transformation of $\mathbf{4}$ into the conjugated linear carbocation $\mathbf{5}$ requires a hydride transfer from the tertiary carbon atom of $\mathbf{4}$. The generally accepted path for such a process involves species $\mathbf{3}$ as the $\mathrm{H}$-acceptor. A specific arrangement of species $\mathbf{3}$ and $\mathbf{4}$ in close proximity to each other within the zeolite pores is required for the intermolecular hydride transfer. Although both the computed enthalpies suggest that such a reaction is favorable, such a process seems sterically very challenging, especially in the case of H-ZSM-5. Therefore we consider an alternative path, in which an acidic proton of the zeolite plays the role of $\mathrm{H}$-acceptor. In this case, the hydridic $\mathrm{H}$-atom from the tertiary carbon of $\mathbf{4}$ directly recombines with the zeolitic proton, resulting in the conjugated carbocation 5 and a dihydrogen molecule. The corresponding reaction energies are $c a .100 \mathrm{~kJ} \mathrm{~mol}^{-1}$ higher when compared to the conventional path (Table 4). However, since the alternative reaction pathway involves formation of a gaseous $\mathrm{H}_{2}$ species, one expects the finite temperature and entropic contribution to be substantial in this case. To verify this, we estimated Gibbs free energy changes at $373 \mathrm{~K}\left(\Delta G^{\circ, \mathrm{vdW}_{373 \mathrm{~K}}}\right)$ for the conventional bimolecular $(\mathbf{4}+\mathbf{3} \rightarrow \mathbf{5}+\mathbf{6})$ and the direct $\left(\mathbf{4} \rightarrow \mathbf{5}+\mathrm{H}_{2}\right)$ hydride transfer reaction in zeolites H-ZSM-5 and $\mathrm{Y}$. The $\mathrm{vdW}$-corrected $\Delta G^{\circ, \mathrm{vdW}}{ }_{373 \mathrm{~K}}$ values for the former path equal -33 and $-68 \mathrm{~kJ} \mathrm{~mol}^{-1}$, whereas the free energy changes for the direct hydride transfer equal -64 and $-45 \mathrm{~kJ} \mathrm{~mol}^{-1}$, respectively, for H-ZSM-5 and $\mathrm{Y}$ zeolites. These data convincingly show that the direct hydride transfer $\left(\mathbf{4} \rightarrow \mathbf{5}+\mathrm{H}_{2}\right)$ is substantially favored within the narrow pores of H-ZSM-5, whereas in the larger faujasite supercage the bimolecular reaction $(\mathbf{4}+\mathbf{3} \rightarrow \mathbf{5}+\mathbf{6})$ is the preferred reaction path.

The formation of the conjugated linear carbocation $\mathbf{5}$ in zeolites is in competition with the formation of the cyclic carbocation 7. A comparison of the overall formation energies of the linear species $\mathbf{5}$ and the cyclic product $\mathbf{7}$ from species $\mathbf{3}$ via the direct $\mathrm{H}$-transfer (reactions $\mathbf{3} \rightarrow \mathbf{5}+\mathrm{H}_{2}$ and $\mathbf{3} \rightarrow \mathbf{7}+\mathrm{H}_{2}$, respectively) indicates that in the case of $\mathrm{H}-\mathrm{Y}$ the formation of the cyclic carbocation $\left(3 \rightarrow 7+\mathrm{H}_{2}, \Delta E^{\mathrm{PBE}+\mathrm{vdW}}=\right.$ $\left.-38 \mathrm{~kJ} \mathrm{~mol}^{-1}\right)$ is strongly favored over the formation of the linear product $\left(\mathbf{3} \rightarrow \mathbf{5}+\mathrm{H}_{2}, \Delta E^{\mathrm{PBE}+\mathrm{vdW}}=+31 \mathrm{~kJ} \mathrm{~mol}^{-1}\right)$. The situation is reversed when the transformations take place within H-ZSM-5. Although in this case both reactions are endothermic $\left(\mathbf{3} \rightarrow \mathbf{5}+\mathrm{H}_{2}, \Delta E^{\mathrm{PBE}+\mathrm{vdW}}=+28 \mathrm{~kJ} \mathrm{~mol}^{-1}\right.$ and $\left.3 \rightarrow 7+\mathrm{H}_{2}, \Delta E^{\mathrm{PBE}+\mathrm{vdW}}=+46 \mathrm{~kJ} \mathrm{~mol}^{-1}\right)$, the specific spatial constraints of the H-ZSM-5 microporous environment disfavor the formation of the cyclic species 7. When vdW interactions are taken into account the linear carbocation $\mathbf{5}$ is more stable by $18 \mathrm{~kJ} \mathrm{~mol}^{-1}$ than cyclic species 7 . Since the equilibrium between 5 and 7 does not involve a change in the number of species, the finite temperature and the entropy corrections do not change the qualitative picture described above. 
These findings are in line with the experimental observations. Indeed, the UV-Vis spectra upon styrene oligomerization in $\mathrm{H}-\mathrm{Y}$ evidence formation of only the cyclic carbocation 7 , whereas within H-ZSM-5, also the formation of the conjugated linear carbocation $\mathbf{5}$ is observed. The major factors that influence the product distribution are the spatial constraints of the microporous environment and accordingly different degrees of stabilization of different hydrocarbon species by vdW contacts (Table 4). For that reason we propose that in the case of H-ZSM-5 formation of cyclic species 7 takes place at the more open sites near the edges of the zeolite microcrystals. This reasoning can be supported by the fact that the formation of the cyclic carbocation is hardly observed when the reaction is performed on large $(20 \times 20 \times 100 \mu \mathrm{m}) \mathrm{H}-\mathrm{ZSM}-5$ crystals. $^{31}$ Due to the fact that in these large zeolite crystals the external surface area is very small compared to the micropore area, hardly any cyclic product is being formed. In the nanometre-sized (200-600 nm crystallites) H-ZSM-5 materials described in this study the external surface area is much larger, which enhances the formation of the cyclic product.

\section{Conclusions}

We have demonstrated that the acid-catalyzed oligomerization of 4-fluorostyrene provides a suitable probe reaction to monitor the acidity of porous solid materials with UV-Vis spectroscopy. The different reaction rate constants obtained for the three products formed within the pore system of various H-ZSM-5 materials with different $\mathrm{Si} / \mathrm{Al}$ ratios all show the same trend, i.e. an optimum in reactivity/acidity is found for a H-ZSM-5 sample with a $\mathrm{Si} / \mathrm{Al}$ ratio of 25 . The developed method was extended to the examination of zeolite $\mathrm{H}-\mathrm{Y}$ samples. From these measurements it is clear that only the cyclic dimer is formed in the supercages of zeolite $\mathrm{H}-\mathrm{Y}$ materials.

The results obtained with UV-Vis spectroscopy were further rationalized by quantum chemical calculations using Density Functional Theory. These DFT calculations on the oligomerization reaction of 4-fluorostyrene in the pores of H-ZSM-5 and H-Y show that differences in formation energy for the linear dimer and the cyclic dimer explain the different product distributions in the two framework types. In the pores of H-ZSM-5 both the linear and cyclic product can be formed with reasonable energies. The formation of the linear dimer is energetically slightly favored. The direct hydride transfer pathway is favored over the bimolecular hydride transfer pathway since it involves the formation of a gaseous $\mathrm{H}_{2}$ species that causes a gain in entropy. In the cages of $\mathrm{H}-\mathrm{Y}$ the formation of the cyclic dimer is energetically strongly favored over the formation of the linear dimer. These calculations support the observations made with UV-Vis, which indicate that only the cyclic dimer is formed in the supercages of $\mathrm{H}-\mathrm{Y}$, while the H-ZSM-5 channels accommodate both the cyclic and the linear dimer.

\section{Acknowledgements}

We thank Albemarle Catalysts for financial support and for providing ZSM-5 and zeolite Y samples. E. S. acknowledges
NWO-CW for his VENI grant. NCF is acknowledged for providing computational resources with financial support from NWO.

\section{References}

1 A. Corma, Chem. Rev., 1995, 95, 559-614.

2 A. Corma, Chem. Rev., 1997, 97, 2373-2419.

3 A. Bhan and E. Iglesia, Acc. Chem. Res., 2008, 41, 559-567.

4 M. Bevilacqua, T. Montanari, E. Finocchio and G. Busca, Catal. Today, 2006, 116, 132-142.

5 K. J. Balkus, Jr., A. K. Khanmamedova and R. Woo, J. Mol. Catal. A: Chem., 1998, 134, 137-143.

6 S. C. Loureiro Dias, J. L. de Macedo and J. Alves Dias, Phys. Chem. Chem. Phys., 2003, 5, 5574-5579.

7 D. Fărcaşiu, R. Leu and A. Corma, J. Phys. Chem. B, 2002, 106, 928-932.

8 R. von Balmoos, D. H. Harris and J. S. Magee, in Handbook of Heterogeneous Catalysis, ed. G. Ertl, H. Knözinger and J. Weitkamp, VCH Verlagsgesellschaft mbH, Weinheim, 1st edn, 1997, vol. 4, pp. 1955-1983.

9 W. E. Farneth and R. J. Gorte, Chem. Rev., 1995, 95, 615-635.

10 W. Vermeiren and J.-P. Gilson, Top. Catal., 2009, 52, 1131-1161.

11 R. Beaumont and D. Barthomeuf, J. Catal., 1972, 26, 218-225.

12 D. Barthomeuf, J. Phys. Chem., 1979, 83, 249-256.

13 R. J. Mikovsky and J. F. Marshall, J. Catal., 1976, 44, 170-173.

14 D. Barthomeuf, Mater. Chem. Phys., 1987, 17, 49-71.

15 W.-C. Cheng, E. T. Habib, K. Rajagopalan, T. G. Roberie, R. F. Wormsbecher and M. S. Ziebarth, in Handbook of Heterogeneous Catalysis, ed. G. Ertl, H. Knözinger, F. Schüth and J. Weitkamp, WILEY-VCH Verlag GmbH \& Co, Weinheim, 2nd edn, 2008, vol. 6, pp. 2741-2778.

16 J. Pérez-Ramírez, C. H. Christensen, K. Egeblad, C. H. Christensen and J. C. Groen, Chem. Soc. Rev., 2008, 37, 2530-2542.

17 In situ Spectroscopy in Heterogeneous Catalysis, ed. J. F. Haw, WILEY-VCH, Weinheim, 2002.

18 In situ Spectroscopy of Catalysts, ed. B. M. Weckhuysen, American Scientific Publishers, Stevenson Ranch, 2004.

19 H. G. Karge, in Handbook of Heterogeneous Catalysis, ed. G. Ertl, H. Knözinger, F. Schüth and J. Weitkamp, WILEY-VCH, Weinheim, 1st edn, 2008, vol. 2, pp. 1096-1135.

20 G. T. Haller, Catal. Rev. Sci. Eng., 1981, 23, 477-504.

21 J. W. Ward, J. Catal., 1970, 17, 355-358.

22 F. Thibault-Starzyk, I. Stan, S. Abelló, A. Bonilla, K. Thomas, C. Fernandez, J.-P. Gilson and J. Pérez-Ramírez, J. Catal., 2009, 264, 11-14.

23 J. A. Martens and P. A. Jacobs, Zeolites, 1986, 6, 334-348.

24 J. W. Ward, J. Catal., 1968, 11, 259-260.

25 L. Forni, Catal. Rev. Sci. Eng., 1973, 8, 65-115.

26 A. Auroux, Y. S. Yin, J. C. Vedrine and L. Benoist, Appl. Catal., 1988, 36, 323-330.

27 D. J. Parrillo, C. Lee and R. J. Gorte, Appl. Catal., A, 1994, 110, 67-74.

28 M. Hunger, D. Freude and H. Pfeifer, J. Chem. Soc., Faraday Trans., 1991, 87, 657-662.

29 M. H. F. Kox, E. Stavitski and B. M. Weckhuysen, Angew. Chem., Int. Ed., 2007, 46, 3652-3655.

30 M. H. F. Kox, E. Stavitski, J. C. Groen, J. Pérez-Ramírez, F. Kapteijn and B. M. Weckhuysen, Chem.-Eur. J., 2008, 14, 1718-1725.

31 E. Stavitski, M. H. F. Kox and B. M. Weckhuysen, Chem.-Eur. J., 2007, 13, 7057-7065.

32 G. Kresse and J. Furthmuller, Phys. Rev. B: Condens. Matter, 1996, 54, 11169-11186.

33 J. P. Perdew, K. Burke and M. Ernzerhof, Phys. Rev. Lett., 1996, 77, 3865-3868.

34 G. Kresse and D. Joubert, Phys. Rev. B: Condens. Matter Mater. Phys., 1999, 59, 1758-1775.

35 P. E. Blochl, Phys. Rev. B: Condens. Matter, 1994, 50, 17953-17979.

36 H. J. Monkhorst and J. D. Pack, Phys. Rev. B. Solid State, 1976, 13, 5188-5192. 
37 P. Mignon, E. A. Pidko, R. A. van Santen, P. Geerlings and R. A. Schoonheydt, Chem.-Eur. J., 2008, 14, 5168-5177.

38 E. A. Pidko, P. Mignon, P. Geerlings, R. A. Schoonheydt and R. A. van Santen, J. Phys. Chem. C, 2008, 112, 5510-5519.

39 T. Demuth, L. Benco, J. Hafner, H. Toulhoat and F. Hutschka, J. Chem. Phys., 2001, 114, 3703-3712.

40 A. M. Vos, X. Rozanska, R. A. Schoonheydt, R. A. van Santen, F. Hutschka and J. Hafner, J. Am. Chem. Soc., 2001, 123, 2799-2809.

41 S. Svelle, C. Tuma, X. Rozanska, T. Kerber and J. Sauer, J. Am. Chem. Soc., 2009, 131, 816-825.

$42 \mathrm{Ch}$. Baerlocher and L. B. McCusker, Database of Zeolite Structures, http://www.iza-structure.org/databases/.

43 D. H. Kitson and A. T. Hagler, Biochemistry, 1988, 27, 7176-7180.

44 P. Dauber-Osguthorpe, V. A. Roberts, D. J. Osguthorpe, J. Wolff, M. Genest and A. T. Hagler, Proteins: Struct., Funct., Genet., 1988, 4, 31-47.

45 J. D. Gale, Z. Kristallogr., 2005, 220, 552-554.

46 T. J. Hou, L. L. Zhu and X. J. Xu, J. Phys. Chem. B, 2000, 104, 9356-9364.

47 H. Jobic, H. Ramanan, S. M. Auerbach, M. Tsapatsis and P. Fouquet, Microporous Mesoporous Mater., 2006, 90, 307-313.
48 E. A. Pidko and R. A. van Santen, in Zeolites and Catalysis: Synthesis, Reactions and Applications, ed. J. Cejka, A. Corma and S. I. Zones, Wiley-VCH, Weinheim, 1st edn, 2010, vol. 1, pp. 301-333.

49 A. Corma and H. García, J. Chem. Soc., Dalton Trans., 2000, 1381-1394.

50 F. L. Cozens, R. Bogdanova, M. Régimbald, H. García, V. Martí and J. C. Scaiano, J. Phys. Chem. B, 1997, 101, 6921-6928.

51 V. Fornés, H. García, V. Martí and L. Fernández, Tetrahedron, 1998, 54, 3827-3832.

52 A. R. Taylor, G. W. Keen and E. J. Eisenbraun, J. Org. Chem., 1976, 42, 3477-3480.

53 L. Fernández, V. Martí and H. García, Phys. Chem. Chem. Phys., 1999, 1, 3689-3695.

54 E. Stavitski, M. H. F. Kox, I. Swart, F. M. F. de Groot and B. M. Weckhuysen, Angew. Chem., Int. Ed., 2008, 47, 3543-3547.

55 M. J. Rice, A. K. Chakraborty and A. T. Bell, J. Catal., 1999, 186, 222-227.

56 Y. Zhao and D. G. Truhlar, J. Chem. Theory Comput., 2005, 1, 415-432. 